Contract \# N00014-14-C-0020

Pilot-in-the-Loop CFD Method Development

Progress Report (CDRL A001)

Progress Report for Period: April 21, 2016 to July 20, 2016

PI: Joseph F. Horn

814-865-6434

joehorn@psu.edu

Performing Organization:

The Pennsylvania State University

Department of Aerospace Engineering

231C Hammond Building

University Park, PA 16802

Attn: Joseph F. Horn

Phone: 814-865-6434, Fax: 814-865-7092

Email: joehorn@psu.edu

\title{
Prepared under:
}

Contract Number N00014-14-C-0020

2012 Basic and Applied Research in Sea-Based Aviation

ONR \#BAA12-SN-028

CDRL A001

DISTRIBUTION STATEMENT A: Distribution Approved for public release; distribution is unlimited. 
ENCLOSURE NUMBER I

CONTRACT DATA REQUTREMENTS LIST

INSTRUCTIONS FOR DISTRIBUTION

\section{DISTRIBUTION OF TECHNICAL REPORTS, FINAL REPORT, THEORY AND USER \\ MANUAL FOR SOFTWARE \\ (A SF 298 must accompany the final report)}

\begin{tabular}{|l|c|c|c|}
\hline \multicolumn{1}{|c|}{ ADDRESSEE } & \multicolumn{2}{|c|}{ NUMBER OF COPIES } \\
\hline $\begin{array}{l}\text { COR: Mr. John Kinzer } \\
\text { ONR Code 351 } \\
\text { E-Mail: john.kinzer@navy.mil }\end{array}$ & $\begin{array}{c}\text { DODAAC } \\
\text { CODE }\end{array}$ & $\begin{array}{c}\text { UNCLASSIFIED } \\
\text { /UNLMMTED }\end{array}$ & $\begin{array}{c}\text { UNCLASSIFIED/ } \\
\text { LIMITED AND } \\
\text { CLASSIFIED }\end{array}$ \\
\hline $\begin{array}{l}\text { Program Officer: Dr. Judah Milgram } \\
\text { ONR Code 351 } \\
\text { E-Mail: judah.milgram@navy.mil }\end{array}$ & N00014 & 1 & 1 \\
\hline $\begin{array}{l}\text { Program Officer: Ms. Susan Polsky } \\
\text { NAVAIR 4.3.2.1 } \\
\text { E-Mail: susan.polsky@navy.mil }\end{array}$ & N00024 & 1 & 1 \\
\hline $\begin{array}{l}\text { Administrative Contracting Officer* } \\
\text { E-Mail: dcmaphiladelphiacasd@dcma.mil }\end{array}$ & S3915A & 1 & 1 \\
\hline $\begin{array}{l}\text { Director, Naval Research Lab } \\
\text { Attn: Code 5596 } \\
\text { 4555 Overlook Avenue, Sw } \\
\text { Washington, D.C. 20375-5320 } \\
\text { E-mail: reports@library.nrl.navy.mil }\end{array}$ & N00173 & 1 & 1 \\
\hline $\begin{array}{l}\text { Defense Technical Information Center } \\
\text { 8725 John J. Kingman Road } \\
\text { STE 0944 } \\
\text { Ft. Belvoir, VA 22060-6218 } \\
\text { E-mail: tr@dtic.mil }\end{array}$ & HJ4701 & 1 & \\
\hline
\end{tabular}

* Send only a copy of the transmittal letter to the Administrative Contracting Officer; do not send actual reports to the Administrative Contracting Officer.

ELECTRONIC SUBMISSIONS OF TECHNICAL REPORTS IS PREFERRED AND ENCOURAGED. ELECTRONIC SUBMISSION SHOULD BE SENT TO THE E-MAIL ADDRESSES PROVIDED IN THE ABOVE TABLE, HOWEVER PLEASE NOTE THE FOLLOWING:

- Only Unlimited/Unclassified document copies may be submitted by e-mail.

- Unclassified/Limited has restricted distribution and a classified document (whether in its entirety or partially) is to be distributed in accordance with classified material handling procedures.

- Electronic submission to DIRECTOR, NAVAL RESEARCH LAB, shall be unclassified/unlimited reports and 30 pages or less. If unclassified and more than 30 pages, 


\section{Section I: Project Summary}

\section{Overview of Project}

This project is performed under the Office of Naval Research program on Basic and Applied Research in Sea-Based Aviation (ONR BAA12-SN-0028). This project addresses the Sea Based Aviation (SBA) virtual dynamic interface (VDI) research topic area "Fast, high-fidelity physics-based simulation of coupled aerodynamics of moving ship and maneuvering rotorcraft". The work is a collaborative effort between Penn State, NAVAIR, and Combustion Research and Flow Technology (CRAFT Tech). This document presents progress at Penn State University.

All software supporting piloted simulations must run at real time speeds or faster. This requirement drives the number of equations that can be solved and in turn the fidelity of supporting physics based models. For real-time aircraft simulations, all aerodynamic related information for both the aircraft and the environment are incorporated into the simulation by way of lookup tables. This approach decouples the aerodynamics of the aircraft from the rest of its external environment. For example, ship airwake are calculated using CFD solutions without the presence of the helicopter main rotor. The gusts from the turbulent ship airwake are then re-played into the aircraft aerodynamic model via look-up tables. For up and away simulations, this approach works well. However, when an aircraft is flying very close to another body (i.e. a ship superstructure) significant aerodynamic coupling can exist. The main rotor of the helicopter distorts the flow around the ship possibly resulting significant differences in the disturbance on the helicopter. In such cases it is necessary to perform simultaneous calculations of both the Navier-Stokes equations and the aircraft equations of motion in order to achieve a high level of fidelity. This project will explore novel numerical modeling and computer hardware approaches with the goal of real time, fully coupled CFD for virtual dynamic interface modeling \& simulation.

Penn State is supporting the project through integration of their GENHEL-PSU simulation model of a utility helicopter with CRAFT Tech's flow solvers. Penn State will provide their piloted simulation facility (the VLRCOE rotorcraft simulator) for preliminary demonstrations of pilot-in-the-loop simulations. Finally, Penn State will provide support for a final demonstration of the methods on the NAVAIR Manned Flight Simulator.

\section{Activities this period}

During this reporting period, a new dataset of the SFS2 ship airwake was generated for 30 degree WOD at 25 knots. This new dataset will be used in the Penn State Flight Simulator facility to perform real-time pilot-in-the-loop simulations and the results will be compared with non-real-time fully coupled simulations for the same cases. Additionally, the implementation of the tail rotor to the coupling interface as an actuator disk has been recently completed.

\section{Generation of SFS2 30 degree WOD Ship Airwake Dataset}

The unsteady flow over the SFS2 (Simple Frigate Shape 2) ship model was obtained using CRAFT Tech's CRUCNH CFD solver. The computational domain that had been used for the 0 degree WOD ship airwake case was modified for the 30 degree WOD case. The refined region behind the ship deck was expanded on both sides of the ship since a wider shedding vorticity distribution was expected.

A small subdomain ( $335 \mathrm{ft} \times 200 \mathrm{ft} \times 85 \mathrm{ft}$ ) was extracted from the full-scale domain. This subdomain is located right behind the superstructure of the ship and lies between $+365-+700 \mathrm{ft}$. in the $\mathrm{x}$-axis, $-100-$ 
$+100 \mathrm{ft}$. in the $\mathrm{y}$-axis and $+15-100 \mathrm{ft}$. in $\mathrm{z}$-axis with a uniform node spacing of $5 \mathrm{ft}$ in all directions. The airwake axes directionality is as follows: $\mathrm{x}$ - positive aft, $\mathrm{y}$ - positive starboard, $\mathrm{z}$ - positive up.

The grid used for the CFD analysis was an unstructured grid. However, real-time GENHEL-PSU supports a structured grid type for fster interploation. So the CFD results were converted to a structured grid type. MATLAB was used to interpolate the scattered data to a uniform structured grid. Linear interpolation methods were used for the data conversion. Figure 1 shows the unstructured CFD data, and the interpolated sub-domain extracted from these data.

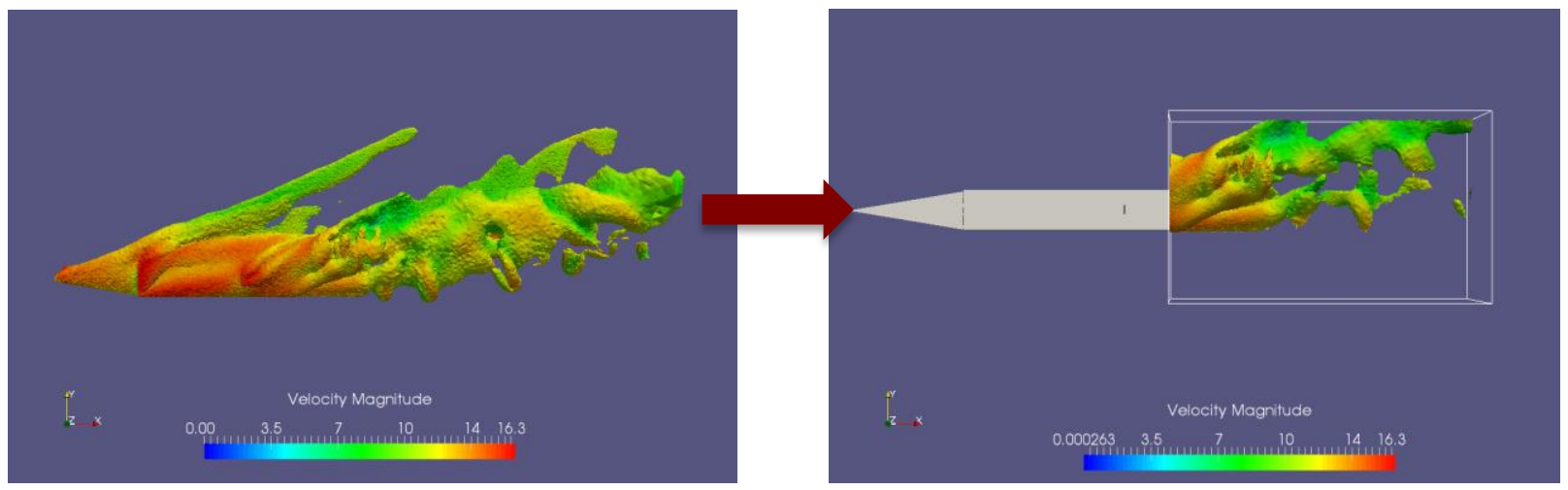

Figure 1 - SFS2 ship airwake distribution at $50^{\text {th }}$ of the simulation, a) actual unstructured CFD data (left), b) interpolated structured sub-domain (right)

The SFS2 0 degree WOD ship airwake data was generated in a previous work and more information about the GENHEL-PSU ship airwake module can be obtained from Ref 1 . In order to investigate the flow characteristics of the newly obtained ship airwake data, a set of simulations were performed using the SFS2 0 deg. and $30 \mathrm{deg}$. WOD ship airwake data for a helicopter hovering near the SFS2 ship flight deck. Figure 2 shows the position of the simulated helicopter relative to the SFS2 ship flight deck and the 30 degree ship airwake sub-domain.
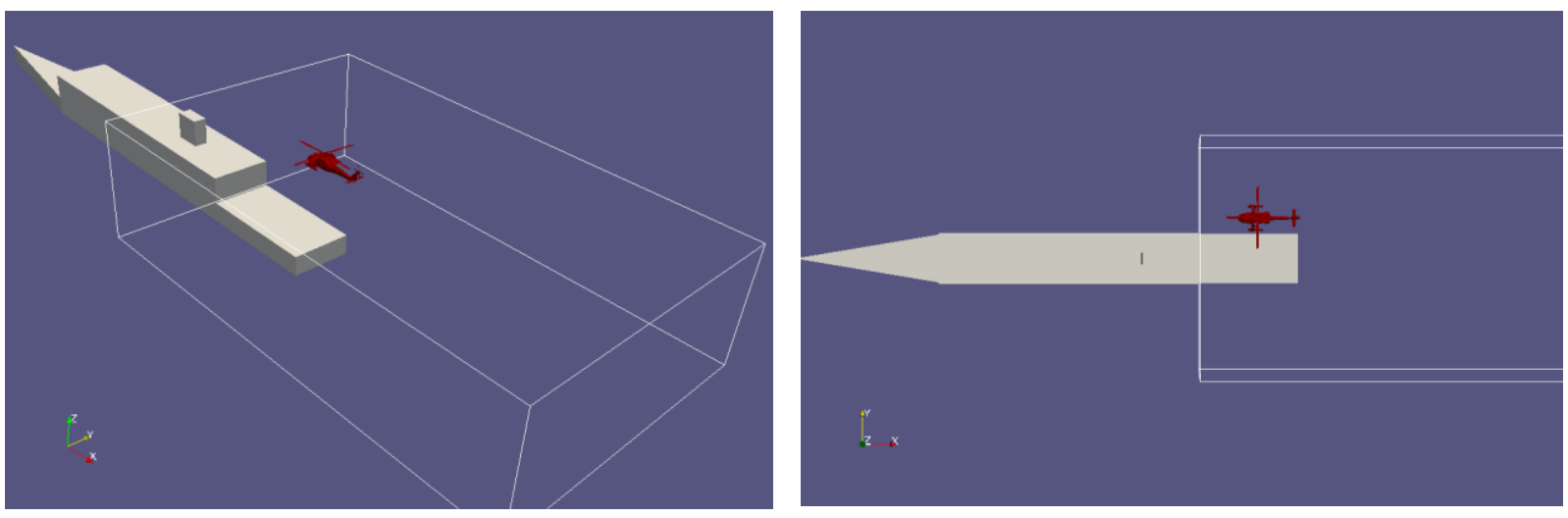

Figure 2 - The position of simulated helicopter relative to the SFS2 ship deck and the sub-domain used for the 30 degree WOD ship airwake data. 

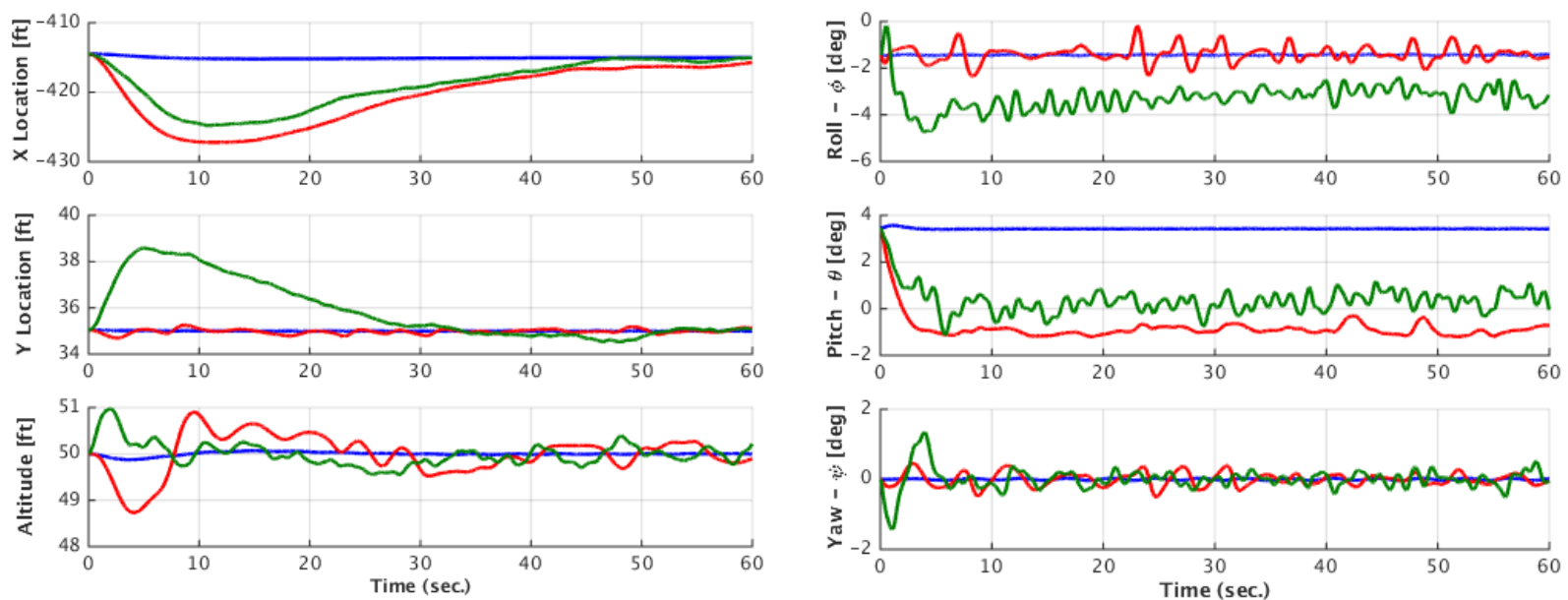

Figure 3 - Variations in the positions of the simulated helicopter, Hover at $x=-415 \mathrm{ft}, y=35 \mathrm{ft}, \mathrm{z}$ $=\mathbf{5 0} \mathrm{ft}$.

Figure 4 - Variations in the attitudes of the simulated helicopter, Hover at $x=-415 \mathrm{ft}, y=35 \mathrm{ft}, \mathrm{z}$ $=\mathbf{5 0} \mathbf{f t}$.
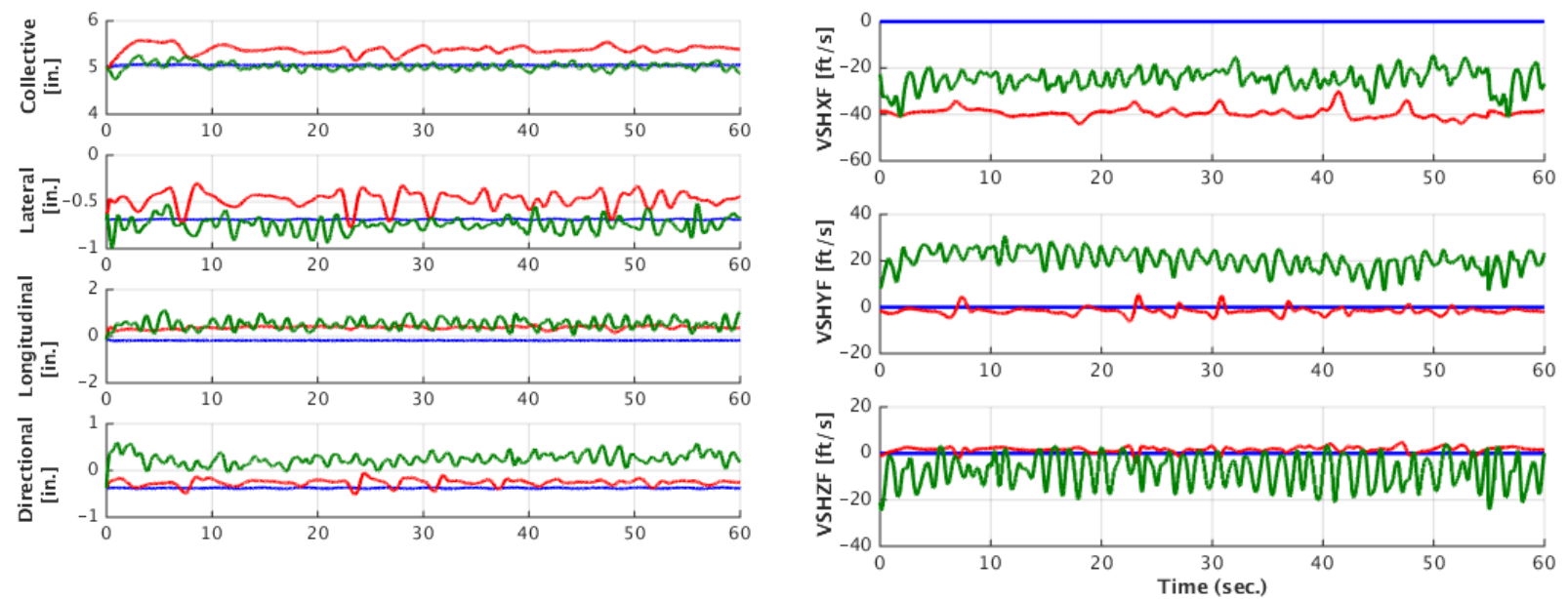

Figure 5 - Variations in the control response of the simulated helicopter, Hover at $x=-415 \mathrm{ft}, y=35 \mathrm{ft}, \mathrm{z}$ $=50 \mathrm{ft}$.

Figure 6 - Variations in the ship airwake velocity components affecting the simulated helicopter, Hover at $x=-415 \mathrm{ft}, y=35 \mathrm{ft}, z=50 \mathrm{ft}$.

Figures 3 to 5 show the time history of the response in position, attitude and the control inputs of the simulated helicopter hovering near the ship flight deck at $\mathrm{x}=-415 \mathrm{ft}, \mathrm{y}=35 \mathrm{ft}, \mathrm{z}=50 \mathrm{ft}$. Simulations performed for no-coupling case, one-way coupled $0 \mathrm{deg}$. WOD and one-way coupled $30 \mathrm{deg}$. WOD cases. Simulation results show that, when the simulated helicopter is disturbed by a 30 degree ship airwake, the disturbances are larger and more frequent. Figure 6 shows the velocity components of the ship airwake disturbing the helicopter during the simulation. It can be seen that the 30 degree WOD ship airwake has higher frequency fluctuations. It should be noted, the flow characteristics of the ship airwake is highly dependent on the location of the helicopter. In these simulations, the helicopter is located at a position where the ship airwake is expected to be stronger, because of the shedding vortices from the superstructure of the ship, originated from the cross winds. 


\section{Implementation of Tail Rotor to the Coupling Interface}

In a conventionally configured helicopter, the larger main rotor provides propulsion and lift, and thus induces significant flow disturbances on the surrounding air. The CFD coupling interface developed under this project has been largely focused on modelling the induced flow due to the main rotor and its aerodynamic interaction with the surrounding flow-field. The smaller tail rotor provides anti-torque and yaw control, and it an also induce significant flow disturbances. Interferences between the wakes and other flow disturbances induced by the helicopter's rotors, fuselage and lifting surfaces can produce strong loads on geometrically distant parts of the configuration. Any unsteadiness or change in these loads as the flight condition of the aircraft is altered, can have a very strong negative influence on the dynamics of the vehicle (Ref 2.).

Previously, in the fully coupled simulations, Navier Stokes CFD was used to calculate the flow field induced by the main rotor as disturbances due to the ship or surrounding terrain. The CFD then serves as the induced inflow model for the main rotor, and calculates the influence of main rotor downwash on the airframe and tail rotor. CFD flow velocities are extracted at four different reference points on the helicopter (fuselage, vertical/horizontal tail, tail rotor) to model the main rotor downwash interaction, but the influence of the tail rotor and airframe on the flow has been ignored. We are now adding the influence of the tail rotor as an actuator disk in the CFD flow solution.

In GENHEL-PSU, the tail rotor is represented by a simplified, closed form, Bailey solution, in which the induced inflow of the tail rotor is calculated via simple momentum theory. When the flight simulation is not coupled with the CFD, the airflow impinging on the tail rotor was developed from the free stream, body angular rate effects, summed with rotor wash and fuselage side wash components calculated from a simple empirical model (Ref 3). In fully coupled simulations, the main rotor downwash component is disabled, so as not "double count" this effect when the CFD solution adds the induced velocity from the main rotor. However, the tail rotor itself did not influence the CFD flow solutions.

In the scope of this quarterly report, the implementation of tail rotor as an actuator disk on the coupling interface has been completed. The implementation process of tail rotor is quite similar to the main rotor implementation: the fully coupled simulation is initialized with Bailey tail rotor equation, which calculates the tail rotor thrust. The tail rotor thrust is then resolved into forces and moments in body axes. Using the tail rotor hub position, the coupling interface creates a uniformly distributed cloud of data points, which represents the entire tail rotor as a permeable disk of equivalent area where forces from the tail rotor are distributed. After several coordinate transformations from body axis to CFD axis frame, GENHEL-PSU transmits the positions and aerodynamic loads of each data point to the CFD solver; and the CFD solver then calculates a velocity field (including the induced velocities from both main and tail rotor) and sends these velocities back to the helicopter simulation model. The tail rotor inflow model will then be disabled when fully coupled with CFD. This implementation doesn't require any modification on the CFD code, since the CFD solver was set up in such a way that requires only the position and aero load of a source point. So from the CFD perspective, this implementation is just an increase in the number of source terms.

With the tail rotor implementation, the coupling interface will provide a better solution of main rotor/tail rotor interaction as well as tail rotor/ground effect interactions. Currently, we have started performing initial tests using this new coupling interface with tail rotor feature. Results will be presented in the next quarterly progress report. 


\section{Significance of Results}

A new dataset of SFS2 ship airwake was generated for 30 degree WOD case. Results have been compared the previously obtained 0 degree WOD ship airwake database using one way coupled simulations for a helicopter hovering near the flight ship deck and results were presented. It was shown that, when the helicopter is disturbed by 30 degree ship airwake, the disturbances are much higher on the helicopter.

The tail rotor implementation to the coupling interface will provide us a better solution of main rotor / tail rotor interactions as well as the tail rotor / ground interactions. Fully coupled simulations results including this new tail rotor implementation will be presented in the next quarterly report.

\section{Plans and upcoming events for next reporting period}

- Implementation of tail rotor to the coupling interface has been completed and we have started performing initial tests using this new improved coupling interface. Simulation results including this new tail rotor implementation will be presented in the scope of next quarterly progress report.

- Currently, there is an ongoing collaborative effort with CRAFT Tech towards applying the latest GPU technology to the coupling interface. CRAFT Tech will implement OpenACC directives to their structured CFD solver, CRAFT CFD. There is a plan to test this new more efficient solver at Penn State clusters with the GPU acceleration support. We hope to get an sufficient speedup in the solver performance of the CFD computations so that a ship airwake model on the order of 5-10 million grid cells can included in the fully coupled simulation framework.

\section{4. $\quad$ References}

[1] Horn, J.F., "Pilot-in-the-Loop CFD Method Development," Progress Report, May 21-June 30, 2014.

[2] Fletcher, T.M. and Brown, R.E., "Main Rotor/Tail Rotor Interaction and Its Implications for Helicopter Directional Control," Journal of the American Helicopter Society, 53(2), pp.125-138, 2008.

[3] Howlett. J., "UH-60A Black Hawk Engineering Simulation Program: Volume I - Mathematical Model," NASA CR166309, 1981.

\section{Transitions/Impact}

No major transition activities during the reporting period.

\section{Collaborations}

We had several tele-conference meetings with CRAFT Tech during this reporting period. We have discussed potential efficiency improvements on the coupling interface. The work continues to involve close collaboration between PSU, CRAFT-Tech, and NAVAIR.

\section{Personnel supported}

Principal investigator: Joseph F. Horn

Graduate Students: Ilker Oruc, PhD Student 


\section{Publications}

Oruc, I., Shenoy, R., Shipman, J., and Horn, J.F., "Toward Real-time Fully Coupled Flight Simulations of the Helicopter/Ship Dynamic Interface," American Helicopter Society Forum 72, West Palm Beach, FL, May 2016.

Oruc, I., Horn, J.F., Shipman, J., and Shenoy, R., "Coupled Flight Dynamics and CFD Simulations of the Rotorcraft/Terrain Interactions," AIAA Modeling and Simulation Technologies Conference, AIAA SciTech, San Diego, CA, January 2016.

(Note that this paper has now been submitted to the AIAA Journal of Aircraft)

Oruc, I., Horn, J.F., Polsky, S., Shipman, J. and Erwin, J., "Coupled Flight Dynamics and CFD Simulations of the Helicopter/Ship Dynamic Interface", American Helicopter Society Forum 71, Virginia Beach, VA, May 2015.

\section{Point of Contact in Navy}

Susan Polsky

Senior Computational Fluid Dynamics Specialist

Naval Air Systems Command Code 4.3.2.1

Applied Aerodynamics \& Store Separation Branch susan.polsky@navy.mil301-342-8575 (Voice)

\section{Acknowledgement/Disclaimer}

This work was sponsored by the Office of Naval Research, ONR, under grant/contract number N0001414-C-0020. The views and conclusions contained herein are those of the authors and should not be interpreted as necessarily representing the official policies or endorsements, either expressed or implied, of the Office of Naval Research, or the U.S. government. 